\title{
Interaction of Small Hydrocarbons with Fusion Relevant Beryllium Thin Films
}

\author{
Bilal Rasul ${ }^{1 a}$, Aroogib \\ RECEIVED ON 20.08.2018, ACCEPTED ON 18.12.2020
}

\begin{abstract}
Ion-surface collision studies are carried out with small deuterated hydrocarbon cations i.e. $\mathrm{CD}_{x}{ }^{+}$with $\mathrm{x}=\mathbf{2 - 4}$ colliding with fusion relevant Beryllium (Be) thin films with ions incident energy as low as $0 \mathrm{eV}$ and as high as $E_{\text {in }}=100 \mathrm{eV}$. Be films are coated on stainless steel surface by the technique of Thermionic Vacuum Arc (TVA); a novel thin film deposition method with primary as well distinguished characteristic of control of ion flux and respective dose towards the substrate. Prior to scattering, methane-d 499 atom \% D is ionized by electron impact and ions are mass and energy analyzed. Ionization and collisions are performed in ultra high vacuum conditions. In these kinds of collision experiments, we have recorded secondary ion mass spectra and plotted respective incident energy resolved abundances of secondary product ions. Relative abundances in percentage of total secondary ions are plotted and it is observed that such beryllium films can accumulate charged hydrocarbon layers as surface adsorbates. These self assembled layers play a primary role in surface-scattering of primary ions. Moreover, it is seen that bond dissociation energy in lighter hydrocarbons is higher than that for heavier species and shows primarily that the deuterium atoms are loosely bounded to carbon atoms in heavier hydrocarbons than in lighter ones.
\end{abstract}

Keywords: Fusion Reactor Walls, Ion-Surface Collisions, Surface Induced Reactions.

\section{INTRODUCTION}

$\mathrm{S}$ tudy of reactive collisions of ions with surfaces is the area accelerated in last few years towards characterizing gaseous molecular ions and also nature of the surfaces. These studies are evidenced by most recent research work on properties of multiplycharged ions, on their spectroscopy and on their gasphase reactivity [1-5]. Considerable interests are taken to study physical sputtering as well chemical sputtering caused by colliding slow ions with hyper thermal energy range (up to $100 \mathrm{eV}$ ) and the processes like Surface Induced Dissociation (SID), Charge Exchange Reactions (CER) and reflection properties have been identified and investigated [6-8]. In addition to being of fundamental importance, reactions of polyatomic ions with surfaces are relevant in applications like modifying surfaces to prepare advanced electronic materials and plasma-wall interactions in fusion plasma [9-12]. A transfer of translational kinetic energy of projectiles into internal modes of energy has been observed during surface collisions of polyatomic ions, causing their dissociation. This energy transfer may help in characterizing the structures of projectile ions as well nature of surfaces $[13,14]$.

In our earlier papers, we have reported SID and CER of hydrocarbon cations and $\mathrm{NH}_{3}{ }^{+}$with a variety of materials including stainless steel and fusion relevant materials like tungsten and others [15-19]. Reflections of hydrocarbons with fusion relevant tungsten (plasma sprayed tungsten) and Carbon Fiber Composite (CFC) surfaces have been studied experimentally [20-22]. An urgent demand for data on collisions of low-energy ( 0 $100 \mathrm{eV}$ ) small hydrocarbon ions $\mathrm{C}_{1}-\mathrm{C}_{3}$ group, with

\footnotetext{
${ }^{1}$ Department of Physics, University of Sargodha, Sargodha, Pakistan.

Email: bilal.rasul@uos.edu.pk (Corresponding Author), baroogaroog04@ gmail.com

This is an open access article published by Mehran University of Engineering and Technology, Jamshoro under CC BY 4.0 International License.
} 
International Thermonuclear Experimental Reactor (ITER) proposed materials i.e. beryllium, carbon and tungsten, motivated us to investigate the said materials through ion-surface collision experiments.

\section{EXPERIMENTAL SETUPS}

\subsection{Thermionic Vacuum Arc (TVA) setup}

Adhesive and dense layers of metals vapors like tungsten $(\mathrm{W})$, beryllium (Be), nickel (Ni) or chromium $(\mathrm{Cr})$ are deposited in this technique, in high vacuum conditions $\left(<10^{-3} \mathrm{~Pa}\right)$. An externally heated tungsten filament with $100 \mathrm{~mA}$ of electron current accelerates electrons towards an anode biased at 1-6 kV i.e Be inside a W holder. A Wehnelt cylinder focuses the said beam and it ignites an electrical discharge at the anode and creates a strong local heating resulting in metal evaporation. These metal vapors are ionized and may cause the expansion of the plasma in the whole available volume. The parameters like filament current, anode voltage, cathode-anode distance and orientation of the anode are the keys to control the discharge conditions, ultimately whole deposition process. Using the optimized parameters like in [23], a deposition rate of about $5 \pm 0.5 \mathrm{~nm} \mathrm{~s}^{-1}$ is achieved.

\subsection{Double focusing mass spectrometer, BESTOF}

Ion-surface collisions experiments were carried out at double focusing sector field mass spectrometer, designed in reverse geometry (i.e. $\mathrm{BE}$ ) and combined with collision chamber containing Surface (S) and linear Time-Of-Flight (TOF) mass spectrometer, namely BESTOF [24-25] at the Institute of Ionphysics and Applied Physics, University of Innsbruck, Austria. $\mathrm{CD}_{x}^{+}[x=2-4]$ ions are produced by a $75 \mathrm{eV}$ electron impact ionization of gaseous $\mathrm{CD}_{4}$ molecules, in a Niertype ion source. Cations produced are accelerated and extracted to about $3 \mathrm{keV}$ of translational kinetic energy and mass and energy analysed. Ion beam current is measured using a Faraday cup installed at exit slit of E-sector. The beam is refocused by a combination of Einzel lens and primary part of the lens stack, held inside the collision chamber. Projectile ions impact at $45^{\circ}$ while the scattering angle was fixed at $91^{\circ}$. The energy spread of the projectile ion beam i.e. $\mathrm{CD}_{x}^{+}[\mathrm{x}=$ 2-4] was about $0.50 \mathrm{eV}$ and the corresponding ion currents were measured as 100-200 pA, focused on a spot of $1 \times 1.5 \mathrm{~mm}^{2}$. In another study, we have simulated ion beam trajectories using SIMION 8.0, and found that about $10 \%$ of the ion current may reach the surface to strike.

Normally, background pressure of the collision chamber is kept less than $10^{-9}$ Torr if the valve between the collision chamber and the mass spectrometer remains closed. However, during our experiments, opening this beam-line valve increases the pressure in this chamber to about $2.0 \times 10^{-8}$ Torr. Under these conditions, the number of collisions between background molecules and the surface is of the order of $10^{12} \mathrm{~mm}^{-2} \mathrm{~s}^{-1}$. When the ion current was kept constant of the order of $10^{11}$ particles $\mathrm{mm}^{-2} \mathrm{~s}^{-1}$, it is worth noticing that the surface would always be covered with a few layers of hydrocarbons.

After reflection in front of the charged surface or collision with adsorbed layers, majority of the product ions resulting from a variety of reaction channels leave surface. A secondary lens stack guides them towards a pulsed deflection and acceleration field, a starting point for the TOF. These secondary ions are detected by a double stage Multi-Channel Plate (MCP), connected to a multi-channel scaler with time resolution of $2 \mathrm{~ns}$ per channel.

\section{RESULTS AND DISCUSSION}

\subsection{Beryllium film structure}

A variety of surface diagnostic techniques are applied to study the structure and composition of Be films at the National Institute of Lasers, Plasma and Radiation Physics, Bucharest, Romania. Roughness of about $300 \pm 50 \mathrm{~nm}$ is observed in Atomic Force Microscopy (AFM) images (Fig. 1) while the Environmental

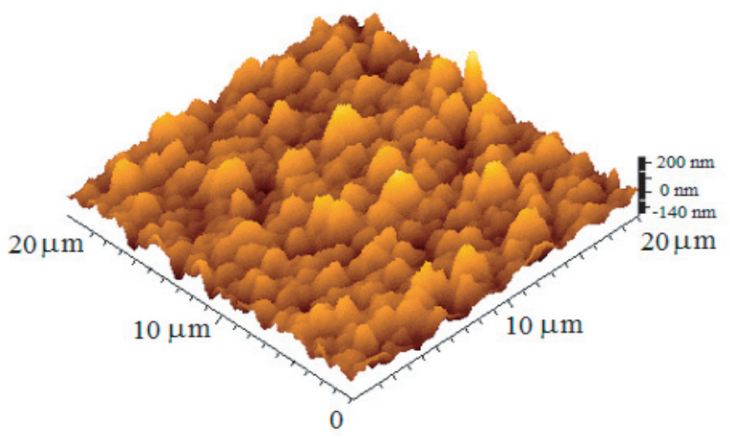

Fig. 1: An AFM image of Be film on stainless steel

Mehran University Research Journal of Engineering and Technology, Vol. 40, No. 3, July 2021 [p-ISSN: 0254-7821, e-ISSN: 2413-7219] 
Scanning Electron Microscopy (ESEM) showed a smooth and pin-hole free Be coating (Fig. 2). The XRay Diffraction (XRD) analysis proved the crystalline structure of the deposited film while some contaminations in the outermost layer $(3 \mathrm{~nm})$ are found when studied by Auger Electron Spectroscopy (AES).

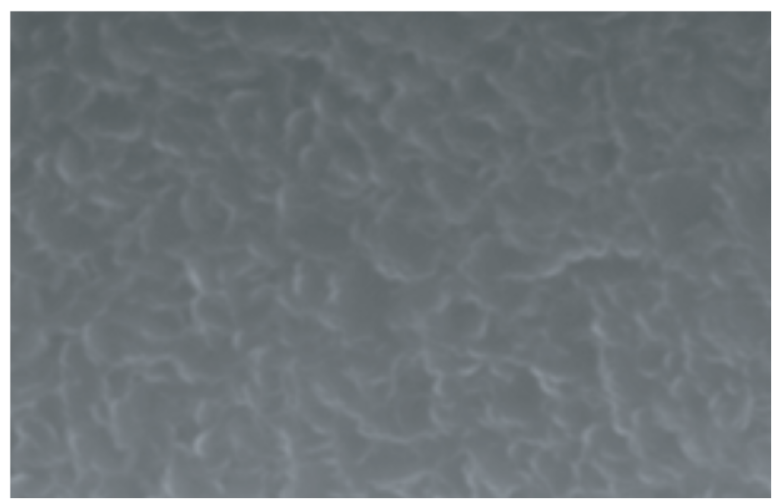

Fig. 2: An SEM image of Be film

\subsection{Ion-surface collisions}

\subsubsection{Surface induced dissociation}

Secondary ion mass spectra are taken by TOF MS explained in experimental section of this paper, after the collisions of $\mathrm{CD}_{2}{ }^{+}, \mathrm{CD}_{3}{ }^{+}$and $\mathrm{CD}_{4}{ }^{+}$ions with beryllium film deposited on stainless steel by TVA.
The incident energy $E_{\text {in }}$ range chosen for the projectile ions is from about $0 \mathrm{eV}$ to a maximum of $100 \mathrm{eV}$ which includes the energy range of hydrocarbons expected in next step fusion devices [26]. In Fig. 3, we show some of the mass spectra recorded at an incident energy of $E_{i n}=30 \mathrm{eV}$. A very few ionic species appear at this low energy, as mentioned there in.

We plot incident Energy Resolved Mass Spectra (ERMS) for surface induced dissociation products after the impact of $\mathrm{CD}_{2}{ }^{+}, \mathrm{CD}_{3}{ }^{+}$and $\mathrm{CD}_{4}{ }^{+}$ion beams with the beryllium film in the incident energy range from about $\mathrm{E}_{\mathrm{in}}=0 \mathrm{eV}-100 \mathrm{eV}$. These are the plots of normalized abundance of the product ions $\frac{I}{\sum I}$ versus incident energy. Fig. 4 summarizes these graphs. Here and onwards, by Appearance Threshold Energy (ATE) of the product ions, we mean the incident energy of the primary ions corresponding to relative abundance of 1 $\%$ of a specific product ion. We see that the overall range of the ATE, to separate one $\mathrm{D}$ atom from the projectile ion, is lower than to separate two and respectively three deuterium atoms. Energy range of appearance threshold at the loss of one $\mathrm{D}$ atom from $\mathrm{CD}_{x}^{+}$lies between $10-20 \mathrm{eV}$ where as this range for the loss of two $\mathrm{D}$ atoms is around $18-68 \mathrm{eV}$ and for three $\mathrm{D}$ atoms this energy range is about $32-80 \mathrm{eV}$.

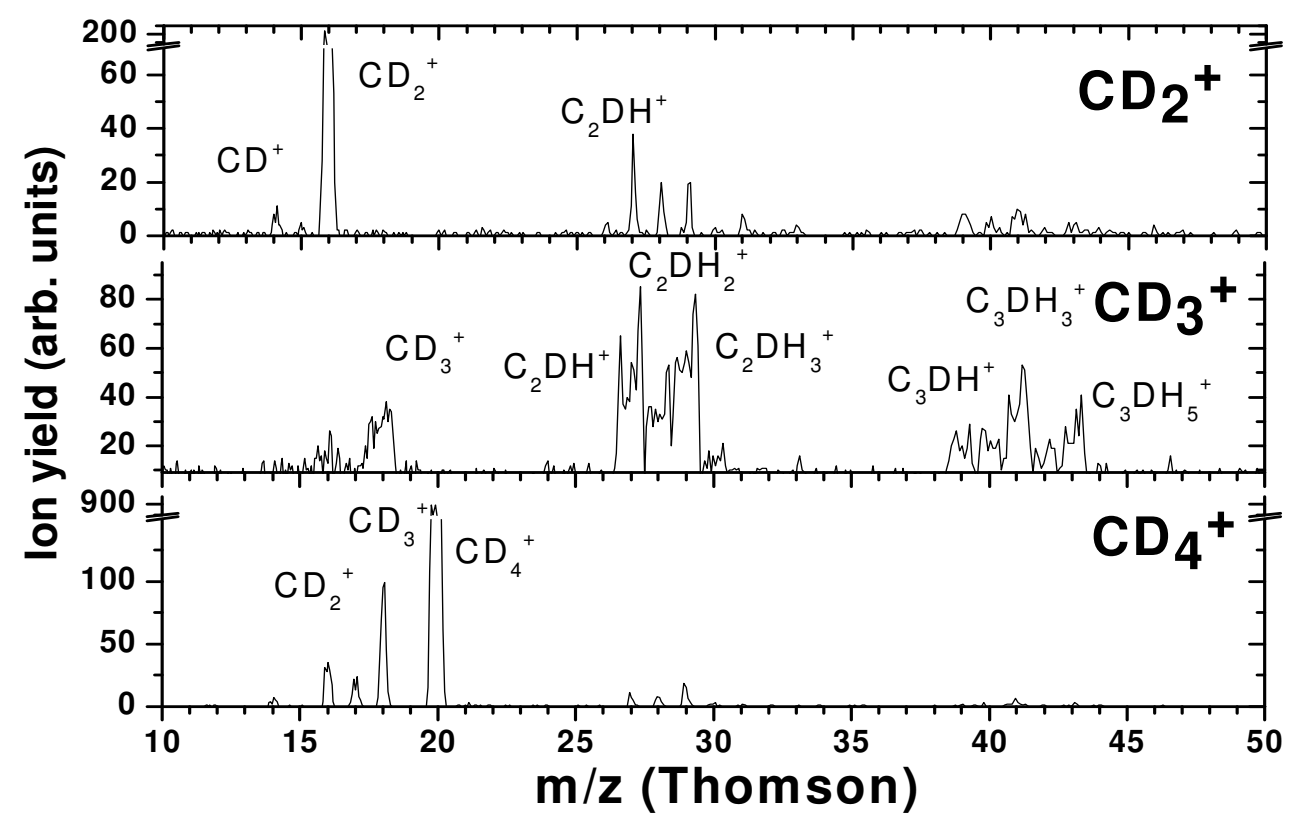

Fig. 3: Secondary ion mass spectra after collisions of $\mathrm{CD}_{\mathrm{x}}{ }^{+}[\mathrm{x}=2-4]$ with Be film deposited on stainless steel surface. These spectra are taken at incident energy of $30 \mathrm{eV}$. 


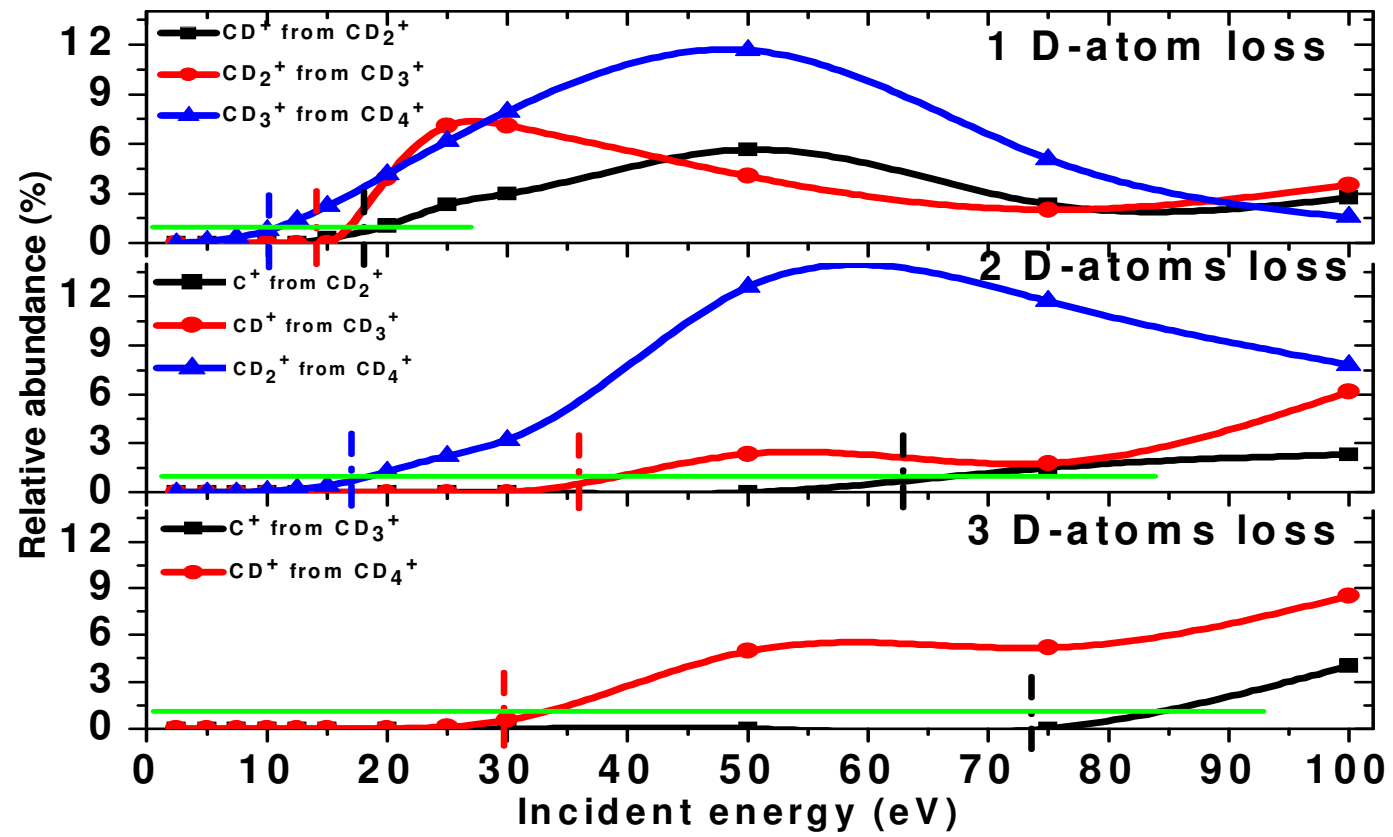

Fig. 4: Energy resolved mass spectra (ERMS) for surface induced dissociation (SID) products after the impact of $\mathrm{CD}_{x}^{+}[x=2-4]$ with Be film. Lines are drawn to guide the eye.

Moreover, we see that the value of ATE for one D atom loss, is lower for heavier projectile ions than in the case of lighter projectiles e.g. ATE for one D-atom loss from $\mathrm{CD}_{4}{ }^{+}$(product ion $\mathrm{CD}_{3}{ }^{+} \mathrm{m} / \mathrm{z} 18$ ) lies at 10 $\mathrm{eV}$ whereas this value is $15 \mathrm{eV}$ for the projectile ion $\mathrm{CD}_{3}{ }^{+}$(product ion $\mathrm{CD}_{2}{ }^{+} \mathrm{m} / \mathrm{z} 16$ ) and in the case of $\mathrm{CD}_{2}{ }^{+}$, this energy threshold lies at $20 \mathrm{eV}$. Such sequential variation in threshold energy is also seen for the separation of two D-atoms i.e. ATE for two Datoms loss from $\mathrm{CD}_{4}{ }^{+}$(product ion $\mathrm{CD}_{2}{ }^{+} \mathrm{m} / \mathrm{z}$ 16) lies at $20 \mathrm{eV}$ and for projectile ion $\mathrm{CD}_{3}{ }^{+}$(product ion $\mathrm{CD}^{+}$ $\mathrm{m} / \mathrm{z} 14$ ), this value is $35 \mathrm{eV}$ whereas in the case of $\mathrm{CD}_{2}{ }^{+}$(product ion $\mathrm{C}^{+} \mathrm{m} / \mathrm{z} 12$ ), this energy threshold lies at $70 \mathrm{eV}$. Similar behavior was observed for the dissociative reaction channels which result in the formation of products at the loss of three $\mathrm{D}$ atoms from the projectile ions. We see that the product ion $\mathrm{CD}^{+}$ $\mathrm{m} / \mathrm{z} 14$ at the loss of three $\mathrm{D}$ atoms from $\mathrm{CD}_{4}{ }^{+}$, appears with $1 \%$ of relative abundance at $32 \mathrm{eV}$ where this energy threshold lies at about $80 \mathrm{eV}$ for the projectile ion $\mathrm{CD}_{3}{ }^{+}$(product ion $\mathrm{C}^{+} \mathrm{m} / \mathrm{z}$ 12). With these observations we can say that the bond dissociation energies always remain at lower values for the heavier hydrocarbon species than those for lighter ones. In other words, the deuterium atoms in smaller hydrocarbons are strongly bonded with the central carbon as compared to their binding in heavier hydrocarbons.

\section{CONCLUSIONS}

Small deuterated hydrocarbon cations $\mathrm{CD}_{2}{ }^{+}, \mathrm{CD}_{3}{ }^{+}$and $\mathrm{CD}_{4}{ }^{+}$are collided with fusion relevant beryllium thin films in the incident energy range from about $0 \mathrm{eV}$ to $100 \mathrm{eV}$. Be is coated on polished stainless steel surfaces by TVA and a variety of experimental techniques reveal that smooth and crack free crystalline coatings are obtained. Secondary ion mass spectra are recorded by linear TOF mass analyzer and respective incident energy resolved mass spectra are presented in this article. We observe that bond dissociation energies are higher for lighter hydrocarbons than for heavier species respectively, C$\mathrm{D}$ bonds seem stronger in lighter hydrocarbons than in heavier ones.

\section{ACKNOWLEDGMENT}

Experiments are carried out at the Institute of Ionphysics and Applied Physics, University of Innsbruck, 6020 Innsbruck, Austria, in collaboration. Whereas mass spectra are resolved and analysed at 
Department of Physics, University of Sargodha, Sargodha, Pakistan. The first author is thankful to Prof. Paul Scheier for his support in performing experiments. Work done by the group of Prof. C. P. Lungu at Romania, in preparing and analysing the surfaces is gratefully acknowledged.

\section{REFERENCES}

1. Metz R.B., "Optical spectroscopy and photo dissociation dynamics of multiply charged ions," International Journal of Mass Spectrometry, Vol. 235, No.2, pp. 131-143, 2004.

2. Herman Z., "Electron transfer processes of atomic and molecular doubly charged ions: information from beam experiments", Molecular Physics, Vol. 111, No. 12-13, pp. 1697-1710, 2013.

3. Cooks R.G., Ast T., Mabud Md. A., "Collisions of polyatomic ions with surfaces", International Journal of Mass Spectrometry and Ion Processes, Vol. 100, pp. 209-265, October 1990.

4. Rabalais J.W., "Low Energy Ion-Surface Interactions”, pp. 55., J. Wiley, New York, 1994.

5. Ada T.E., Hanley L., "Comparing hyperthermal molecular and atomic ion sputtering of adsorbates: $\mathrm{Xe}^{+}$versus $\mathrm{SF}_{5}{ }^{+}$on $\mathrm{NH}_{3} / \mathrm{CO} / \mathrm{Ni}(111)$ ", International Journal of Mass Spectrometry and Ion Processes, Vol. 174, No. 13, pp. 231-244, 1998.

6. Niehus H., Heiland W., Taglauer E., "Low-energy ion scattering at surfaces", Surface Science Reports, Vol. 17, No. 4-5, pp. 213-303, 1993.

7. Grill V., Shen J., Evans C., Cooks R.G., "Collisions of ions with surfaces at chemically relevant energies: Instrumentation and phenomena", Review of Scientific Instruments, Vol. 72, pp. 3149, 2001.

8. Herman Z., "Collisions of slow polyatomic ions with surfaces: the scattering method and results", Journal of American Society of Mass Spectrometry, Vol. 14, No. 12, pp. 1360-1372, 2003.

9. Stork D., Zinkle S.J., "Introduction to the special issue on the technical status of materials for fusion reactor", Nuclear Fusion, Vol. 57, No. 9, pp. 9, 2017.

10. Stork D., Agostini P., Boutard J.L., Buckthorpe D., Diegele E., Dudarev S.L., English C., Federici
G., Gilbert M.R., Gonzalez S., Ibarra A., Linsmeier Ch., Puma A. Li., Marbach G., Morris P.F., Packer L.W., Raj B., Rieth M., Tran M.Q., Ward D.J., Zinkle S.J., "Developing structural, high-heat flux and plasma facing materials for a near-term DEMO fusion power plant: The EU assessment", Journal of Nuclear Materials, Vol. 455, No. 1-3, pp. 277-291, 2014.

11. Zinkle S.J., Blanchard J.P., Callis R.W., Kessel C.E., Kurtz R.J., Lee P.J., McCarthy K.A., Morley N.B., Najmabadi F., Nygren R.E., Tynan G.R., Whyte D.G., Willms R.S., Wirth B.D., "Fusion materials science and technology research opportunities now and during the ITER era”, Fusion Engineering and Design, Vol. 89, No. 7-8, pp. 1579-1585, 2014.

12. Hofer W.O., Roth J., Physical Processes of the Interaction of Fusion Plasmas with Solids, Academic Press, San Diego, CA, 1996.

13. Mair C., Fiegle T., Biasioli F., Wörgötter R., Grill V., Lezius M., Märk T.D., "Surface-induced reactions of polyatomic ions and cluster ions", Plasma Sources, Science and Technology, Vol. 8, No. 2, pp. 191, 1999.

14. Hayward M.J., "Ion/surface collisions for distinction of isomeric $\left[\mathrm{C}_{6} \mathrm{H}_{6}\right]^{+}$and $\left[\mathrm{C}_{6} \mathrm{H}_{6}\right]^{2+}$ ions". Journal of American Chemical Society, Vol. 110, No. 5, pp. 1343-1346, 1988.

15. Qayyum A., Mair C., Tapnual T., Schustereder W., Scheier P., Märk T.D., "Charge exchange and surface-induced dissociation of doubly charged molecular ions $\mathrm{C}_{6} \mathrm{H}_{5}{ }^{2}+, \mathrm{C}_{6} \mathrm{H}_{6}{ }^{2+}$ and $\mathrm{C}_{7} \mathrm{H}_{8}{ }^{2+}$ upon impact on a stainless steel surface", Nuclear Instruments and Methods in Physics Research B, Vol. 205, pp. 714-718, 2003.

16. Pysanenko A., Žabka J., Zappa F., Märk T.D., Herman Z., "Scattering of very slow $(3-10 \mathrm{eV})$ hydrocarbon ions $\mathrm{CD}_{3}{ }^{+}, \mathrm{CD}_{4}{ }^{+}$, and $\mathrm{CD}_{5}{ }^{+}$from room-temperature carbon (HOPG) surfaces", International Journal of Mass Spectrometry, Vol. 273, No. 1-2, pp. 35-47, 2008.

17. Žabka, J., Dolejšek, Z., Roithová, J., Grill, V., Märk, T.D., Herman, Z., "Energy partitioning in collisions of slow polyatomic ions with carbon surfaces", International Journal of Mass Spectrometry, Vol. 213, No. 2-3, pp. 145-156, 2002. 
18. Jašík J., Žabka J., Feketeová L., Ipolyi I., Märk T.D., Herman Z., "Collisions of slow polyatomic ions with surfaces: dissociation and chemical reactions of $\mathrm{C}_{2} \mathrm{H}_{2}{ }^{+*}, \mathrm{C}_{2} \mathrm{H}_{3}{ }^{+}, \mathrm{C}_{2} \mathrm{H}_{4}{ }^{+*}, \mathrm{C}_{2} \mathrm{H}_{5}{ }^{+}$and their deuterated variants $\mathrm{C}_{2} \mathrm{D}_{2}{ }^{+*}$ and $\mathrm{C}_{2} \mathrm{D}_{4}{ }^{+*}$ on room-temperature and heated carbon surfaces", Journal of Physical Chemistry A, Vol. 109, No. 45, pp. 10208-10215, 2005.

19. Jašík J., Roithová J., Žabka J., Pysanenko A., Feketeová L., Ipolyi I., Märk T.D., Herman Z., "Surface-induced dissociation and reactions of dications and cations: Collisions of dications $\mathrm{C}_{7} \mathrm{H}_{8}{ }^{2+}, \mathrm{C}_{7} \mathrm{H}_{7}{ }^{2+}$ and $\mathrm{C}_{7} \mathrm{H}_{6}{ }^{2+}$ and a comparison with the respective cations $\mathrm{C}_{7} \mathrm{D}_{8}{ }^{+}$and $\mathrm{C}_{7} \mathrm{H}_{7}{ }^{+}$." International Journal of Mass Spectrometry, Vol. 249-250, pp. 162-170, 2006.

20. Keim A., Rasul B., Endstrasser N., Scheier P., Märk T.D., Herman Z., "Interaction of small hydrocarbon ions and $\mathrm{Ar}^{+}$with carbon-fibrecomposite surfaces at room temperature", International Journal of Mass Spectrometry, Vol. 306, No. 2-3, pp. 204-209, 2011.

21. Schustereder W., Rasul B., Endstrasser N., Zappa F., Grill V., Scheier P., Märk T.D., "Sticking coefficient and SIMS of hydrocarbons on fusion relevant plasma-sprayed tungsten surfaces", Nuclear Instruments and Methods in Physics Research B, Vol. 258, No.1, pp. 278-281, 2007.

22. Endstrasser N., Rasul B., Schustereder W., Krieger K., Kendl A., Scheier P., Märk T.D.,
"Reflection properties of small hydrocarbons impinging on tungsten and carbon surfaces", Nuclear Instruments and Methods in Physics Research B, Vol. 267, No. 4, pp. 700-703, 2009.

23. Lungu C.P., Mustata I., Zaroshci V., Lungu A.M., Anghel A., Chiru P., Rubel M., Coad P., Mathews G.F., "Beryllium coatings on metals for marker tiles at JET: development of process and characterization of layers", Physica Scripta, Vol. 2007, No. T128, pp. 157, 2007.

24. Endstrasser N., "Electron and Surface Induced Dissociative Process", $\mathrm{PhD}$ Thesis, Institute of Ionphysics and Applied Physics, University of Innsbruck, Austria, 2009.

25. Feketeová L., Tapnual T., Grill V., Scheier P., Roithová J., Herman Z., Märk T.D., "Surfaceinduced dissociation and reactions of cations and dications $\mathrm{C}_{7} \mathrm{H}_{8}{ }^{+/ 2+}, \quad \mathrm{C}_{7} \mathrm{H}_{7}^{+/ 2+}$ and $\mathrm{C}_{7} \mathrm{H}_{6}{ }^{2+}$ : Dependence of mass spectra of product ions on incident energy of the projectiles", International Journal of Mass Spectrometry, Vol. 265, No. 2-3, pp. 337-346, 2007.

26. Dux R., Herrmann A., Kallenbach A., Neu R., Nauhauser J., Maier H., Pugno R., Putterich T., Rohde V., ASDEX Upgrade Team "Plasma surface interaction with tungsten in ASDEX Upgrade", Journal of Nuclear Materials, Vol. 337-339, pp. 852-856-339, 2005. 